\title{
Evidence of Renal Damage in HIV-Infected Patients with High CD4 Counts Following the Use of Traditional Medicine
}

\author{
Numbara Deebii ${ }^{*}$, Ezinne Janefrances Nwankwo' ${ }^{1}$ Ogechukwu Samuel Obi ${ }^{1}$, \\ Mpakaboari Tonye Bekinbo² \\ ${ }^{1}$ Department of Haematology, Blood Transfusion and Immunology, University of Port Harcourt, Port Harcourt, \\ Nigeria \\ ${ }^{2}$ Department of Human Physiology, University of Port Harcourt, Port Harcourt, Nigeria \\ Email: "numbarakomene@yahoo.com
}

Received 22 November 2015; accepted 8 January 2016; published 11 January 2016

Copyright (C) 2016 by authors and Scientific Research Publishing Inc.

This work is licensed under the Creative Commons Attribution International License (CC BY). http://creativecommons.org/licenses/by/4.0/

c) (i) Open Access

\section{Abstract}

Kidney dysfunction is one of the most serious complications resulting from the use of traditional medicine which is common in Africa accounting for about $35 \%$ of renal damage in HIV-infected patients. In this cross sectional study, $250 \mathrm{HIV}$-infected patients were groups as follows: ART GrpA (100), ART + traditional medicine use GrpB (100) and ART treatment naïve + traditional medicine GrpC (50). Tubular dysfunctions were defined when at least two or more of the following abnormalities were repeatedly present: Uricosuria $\geq 0.05 \mathrm{mg} / \mathrm{dl}$, Phosphaturia $\geq 20.0 \mathrm{mg} / \mathrm{dl}$, Glucosuria $\geq 0.1 \mathrm{mg} / \mathrm{dl}$, Proteinuria = positive protein on dipstick urine. Renal dysfunctions were found to be significantly high $(P=0.001)$ in the group of patients treated with ART + traditional medicine. 27 (64.29\%) patients followed by ART treatment naïve patients + traditional medicine; 12 (28.57\%) patients and only $4(7.14 \%)$ patients developed renal toxicity in the ART treatment Grp. But strikingly CD4 counts were also significantly higher in Grp B (683 cell/ul) compared to group A (446 cell/ul) and C (206 cell/ul). Our results show that HIV-infected patients on ART combined with traditional medicine might develop renal abnormalities in the presence of high CD4 counts, in the course of incessant use of traditional medicine. Thus it is important that more research be conducted on its usage among the Black population with HIV infection.

\section{Keywords}

Renal Dysfunction, Traditional Medicine, HIV-Infected Patients, CD4 Counts

\footnotetext{
${ }^{*}$ Corresponding author.
}

How to cite this paper: Deebii, N., Nwankwo, E.J., Obi, O.S. and Bekinbo, M.T. (2016) Evidence of Renal Damage in HIVInfected Patients with High CD4 Counts Following the Use of Traditional Medicine. Journal of Biosciences and Medicines, 4, 54-58. http://dx.doi.org/10.4236/ibm.2016.41007 


\section{Introduction}

HIV-infected patients in both rural and urban settings usually preferred traditional medicine healers before or instead of consultation with a physician [1]-[3]. The reasons for this choice often are multifactorial (e.g., as a result of family or societal pressure, economic pressure, stigmatization, or fright of hospitals) [3]. Traditional healers play a significant role in health care in Africa, and most of their users do not need to resort to Western medicine. Similar to Western medicine, latrogenic complications may arise, however, from the use of traditional therapies. Thus clinicians are usually faced with life threatening renal complications, arising from the used of these traditional medicines. Antiretroviral therapy (ART) has been shown to be highly effective at reducing viral load in people living with HIV. There are a number of symptoms associated with both the treatment and disease which could be addressed through complementary and alternative medicine, including comorbidities (e.g. cardiovascular, liver and renal diseases) and mental health issues (e.g. depression). Since the beginning of the HIV epidemic, traditional medicine has been popular among people living with HIV due to a lack of effective treatments early in the epidemic and a continued lack of access to ART in low and middle-income countries [4]. People living with HIV use traditional medicine for a variety of causes, many related to the use of ART (e.g. poor and antagonistic effects, high cost and lack of availability) [5]. Despite the popularity of traditional medicine, choices by people living with HIV to utilize these types of therapies are often poorly informed [6]. Existing and updated literatures indicate that there is petite research on the frequency of traditional medicine use in Africa and the Caribbean to treat HIV. However, available research indicates that, in African countries with a strong traditional system of medicine, people living with HIV often seek treatment from traditional healers or take herbal medicines prior to accessing clinical care or starting antiretroviral drugs [7]. Herbal medicine in Africa is majorly used as both primary and secondary treatment for HIV and other tropical infectious diseases. It is believed that due to the impending interactions between traditional medicine and antiretroviral drugs and the potentially harmful effects on adherence, it is important that more research be conducted on its usage among the Black population. This will help clinicians and other health care providers to be aware of popular types of traditional medicine and potential interactions, thus creating a reassuring environment where people living with HIV can reveal their traditional medicine use and be informed about their personal health choices.

\section{Material and Methods}

\subsection{Study Protocol}

HIV-infected patients on different treatment regimen as well as those who are treatment naïve were group as follows: Group A (100 HIV infected patients on ART), Group B (100 HIV infected patients on ART combined with traditional medicine), and Group C (54 HIV infected patients who are ART treatment naïve but on traditional medicine).

\subsection{Exclusion Criteria}

Exclusion criteria were as follows: Inability to give informed consent, Diabetes and Hepatitis B/C, known renal disease, patients on aminoglycosides or other nephrotoxic medications and pregnancy.

From every patient's social-demographics details of age, sex, occupation, education, income, and HIV status (CD4 T-lymphocyte count) were recorded at the time of recruitment in to the study. Total prior exposure to traditional medicine was considered as the number of months of uninterrupted anti-HIV treatment up to inclusion. Periods of drug interruption for any reason, if occurring, were discounted. This information was obtained from the patient's treatment file and pharmacy records, as all patients recruited in to the studies had to obtain antiretroviral drugs on a monthly basis from the hospital pharmacy. Treatment was provided without any cost to patients.

\subsection{Samples Collection}

A fasting blood sample was obtained during the protocol visits; the patients also provided a sample of the 24-h urine collection and a morning spot urine sample. Serum and blood samples were analyzed for routine chemistry and a complete blood count. The 24-h urine samples were centrifuged and sent to the central laboratory for evaluation of routine parameters. Carley et al., [8] simple normograms for the calculation of sample size for 
clinical diagnostic study was used for the calculation of sample size for this study.

\subsection{Statistical Analysis}

Continuous values are given as mean and standard deviation while categorical data are given as percentages. The three groups of patients analyzed were first compared using chi-squared for categorical data and parametric tests for continuous variables. The level of significance was 0.05 . All statistical analyses were performed using SPSS v20.0 software package (SPSS inc., Chicago, Illinois, USA).

\subsection{Safety and Ethical Consideration}

The study was carried out in accordance with universal ethical standards and commence only after approval was given by the University of Port Harcourt Ethical Board and the University of Port Harcourt Teaching Hospital Ethical Committee. All data generated were kept in strict confidentiality.

\section{Results}

\section{Characteristics of Patients}

A total of 250 HIV patients were recruited for the study. At recruitment, 100 patients were under ART (Group A), 100 on ART combined with traditional medicine (Group B) and 50 were ART treatment naïve patients on traditional medicine (Group C).

Tubular dysfunction were defined when at least two or more of the following abnormalities were repeatedly present; Uricosuria $\geq 0.05 \mathrm{mg} / \mathrm{dl}$, Phosphaturia $\geq 20.0 \mathrm{mg} / \mathrm{dl}$, Glucosuria $\geq 0.1 \mathrm{mg} / \mathrm{dl}$, Proteinuria = positive protein on dipstick urine. The mean age of the distinct patients' populations include: ART only (Group A) 31.23 years, ART and Traditional medicine (Group B) 32.32 years, and ART treatment-naïve and traditional medicine (Group C) 31.34 years, thedifferences between the groups were not statistically significant $(P=0.099)$ as shown in Table 1 . The gender distribution in this study was statistically significant $(P=0.004)$ and were observed to be; 108 (42.52\%) males and 146 (57.48\%) females. Of the 150 patients exposed to traditional medicine, 80 (53.33\%) had been on the drug for 1 - 12 months, 30 (20.00\%) for 13 - 24 months, 25 (16.67\%) for 25 - 36 months and 15 $(10.0 \%)$ for 37 months and above (P-value $=0.01)$ as shown in Table 2.

Our results show renal dysfunction in the study groups to be as follows: Group A, 3 (7.14\%), Group B, 27 (64.29\%) and Group C, 12 (28.57\%) patients and the difference among the groups was statistically significant (P $=0.003$ ) (Table 3). Table 3 also shows values of CD4 of the study groups to be as follows: Group A, 446 ul/cells, Group B, $683 \mathrm{ul} / \mathrm{cells}$, and Group C, $206 \mathrm{ul} /$ cells, the difference was statistically significant $(\mathrm{P}=0.003)$.

Table 1. Age and sex characteristics of the study population.

\begin{tabular}{|c|c|c|c|c|}
\hline & Mean age & No. of patients & Std. deviation & P-value \\
\hline \multicolumn{5}{|l|}{ Sex } \\
\hline Male & 32.07 & 108 (42.52\%) & 7.79 & \\
\hline Female & 31.20 & 146 (57.48\%) & 8.57 & $\begin{array}{c}\text { (Z-test) } \\
\mathbf{P}=\mathbf{0 . 0 0 4}\end{array}$ \\
\hline Total & 31.63 & $250(100 \%)$ & 8.03 & \\
\hline \multicolumn{5}{|c|}{ Regimen group } \\
\hline Grp 1 & 31.23 & $100(40.0 \%)$ & 6.83 & \\
\hline Grp 2 & 32.32 & $100(40.0 \%)$ & 7.32 & $\begin{array}{c}\text { (ANOVA) } \\
\mathbf{P}=\mathbf{0 . 0 9 9}\end{array}$ \\
\hline Grp 3 & 31.34 & $50(20.0 \%)$ & 6.76 & \\
\hline Total & 31.63 & $250(100 \%)$ & 8.01 & \\
\hline
\end{tabular}

Values in parenthesis show the percentage of patients in the study population. 
Table 2. Mean and median age (months) of patients exposed to ART.

\begin{tabular}{|c|c|c|c|c|c|}
\hline ART exposure (months) & No. of patients & Mean age (months) & Std. error of mean & $\%$ of patients & Median age (months) \\
\hline N-ART & 52 & 32.50 & 0.96 & $20.5 \%$ & 31.00 \\
\hline 1 - 12 months & 100 & 35.38 & 0.90 & $39.4 \%$ & 34.00 \\
\hline 13 - 24 months & 48 & 32.99 & 1.03 & $18.9 \%$ & 32.00 \\
\hline 25 - 36 months & 26 & 37.27 & 1.35 & $10.2 \%$ & 37.50 \\
\hline >37 months & 28 & 37.55 & 1.34 & $11.0 \%$ & 35.95 \\
\hline Total & 254 & 34.77 & 0.50 & $100.0 \%$ & 33.10 \\
\hline
\end{tabular}

ANOVA, $\mathrm{P}=0.01$ (Significant).

Table 3. Association between tubular damage and use of traditional medicine.

\begin{tabular}{rccccc}
\hline & & \multicolumn{3}{c}{ Regimen group } & Total \\
\cline { 3 - 5 } & & Grp A & Grp B & Grp A & 208 (100)\% \\
Tubsent & $97(46.63 \%)$ & $73(35.10 \%)$ & $12(28.57 \%)$ & $\mathbf{4 2}(\mathbf{1 0 0 \% )}$ \\
damage & Present & $3(7.14 \%)$ & $27(64.29 \%)$ & $50(20.0 \%)$ & $\mathbf{2 5 0}(\mathbf{1 0 0 \% )}$ \\
& Total & $100(40.0 \%)$ & $100(40.0 \%)$ & $206 \mathrm{ul} / \mathrm{cells}$ & \\
\hline
\end{tabular}

$\mathrm{X}^{2}=3.52, \mathrm{P}=0.001$ (Significant) for renal damage and use of traditional medicine, and $\mathrm{X}^{2}=3.205, \mathrm{P}=0.003$ (Significant) for use of traditional medicine and CD4 counts. Values in parenthesis show percentage of patients.

\section{Discussion}

Despite the limited evidence for benefits of traditional medicine as part of HIV treatment, there remains a high frequency of use among people living with HIV [9] [10]. This level of use is likely explained, at least in part, by findings from studies that revealed high self-report scores related to traditional medicine in terms of its contributions to enhancements in quality of life and relief of specific symptoms, including fever, flu, pain, skin irritations, abdominal pain, nausea, diarrhea, pain, quality of sleep, appetite, increasing body weight, depression and other clinical outcomes [11] [12]. In addition, some findings have suggested that traditional medicine can assist in the treatment of comorbidities such as osteoporosis and atherosclerosis [6]. A systematic review found that the only effective traditional medicine interventions for people living with HIV were stress management-based with the rest having insufficient data to support them [9] [13]. Studies have shown that the rates of traditional medicine use in Africa vary among people living with HIV and ranges from 36 to 68\% [12].

Specifically the use of traditional herbal remedies has been implicated in $35 \%$ of all cases of acute renal failure in Africa [14]-[17]. This figure is likely to be an underestimate of the true incidence because of the secrecy surrounding the use of traditional remedies. Mortality in this group of patients ranges from 24\% to $75 \%$ [1] [15], but long-term renal outcomes after herbal toxin-associated ARF rarely have been described. In our series of patients study, renal dysfunction was evidence in 42 patients, of which this dysfunction was more prominent in the group of patients treated with ART combined with traditional medicine, 27 (64.29\%), second by the group of patients treated with traditional medicine but never exposed to ART, 12 (28.57\%) compared to patients on ART only, 3 (7.14\%). From our result patients treated with ART combined with traditional medicine have a higher CD4 counts (683 cells/ul) compared to patients on ART only (446 cells/ul). Thus it's seem that traditional medicine helps boast immunity and but its counter interaction seem to caused renal dysfunction. Again it is assume that the unguided doses of traditional medicine to which these patients are exposed to might likely be the cause of this renal dysfunction. Consequently it is likely that, renal dysfunction might had persisted for several days before presentation.

\section{Conclusion}

In conclusion, it is extremely likely that the cause of renal dysfunction in our patients was due to the use of traditional medicine administered as an additional remedy for the treatment of HIV infection. We believe that similar analyses of herbal remedies associated with renal damage would identify potentially toxic substances. The 
ultimate aim would be to develop a strategy to increase awareness and decrease the use of toxic traditional therapies in the treatment of HIV, reducing the incidence of renal damage and decreasing the demands placed on already toxic traditional therapies.

\section{Acknowledgements}

We thank the study participants; Mr. Kanee Rogers Bariture, for help in manuscript preparation; and Njoku, Bestman, for technical assistance.

\section{Conflict of Interest}

The authors confirm that this article content has no conflicts of interest.

\section{References}

[1] Buchanan, N. and Cane, R.D. (1976) Poisoning Associated with Witchdoctor Attendance. South African Medical Journal, 50, 1138-1140.

[2] Gold, C.H. (1980) Acute Renal Failure from Herbal and Patent Remedies in Blacks. Clinical Nephrology, 14, $128-134$.

[3] Wright, S.V. (1997) An Investigation into the Causes of Absconding among Black African Breast Cancer Patients. South African Medical Journal, 87, 1540-1543.

[4] Owen-Smith, A., DePadilla, L. and DiClemente, R. (2011) The Assessment of Complementary and Alternative Medicine Use among Individuals with HIV: A Systematic Review and Recommendations for Future Research. Journal of Alternative \& Complementary Medicine, 17, 789-796. http://dx.doi.org/10.1089/acm.2010.0669

[5] Liu, J.P., Manheimer, E. and Yang, M. (2005) Herbal Medicines for Treating HIV Infection and AIDS. Cochrane Database of Systematic Reviews, 2005, Article ID: CD003937. http://dx.doi.org/10.1002/14651858.cd003937.pub2

[6] Hoogbruin, A. (2011) Complementary and Alternative Therapy (CAT) Use and Highly Active Antiretroviral Therapy (HAART): Current Evidence in the Literature, 2000-2009. Journal of Clinical Nursing, 20, 925-939. http://dx.doi.org/10.1111/j.1365-2702.2010.03322.x

[7] MacDuff, S., Grodin, M.A. and Gardiner, P. (2011) The Use of Complementary and Alternative Medicine among Refugees: A Systematic Review. Journal of Immigrant and Minority Health, 13, 585-599. http://dx.doi.org/10.1007/s10903-010-9318-8

[8] Carley, S., Dosman, S., Jones, S.R. and Harrison, M. (2005) Simple Nomograms to Calculate Sample Size in Diagnostic Studies. Emergency Medicine Journal, 22, 180-181. http://dx.doi.org/10.1136/emj.2003.011148

[9] Mills, E., Wu, P. and Ernst, E. (2005) Complementary Therapies for the Treatment of HIV: In Search of the Evidence. International Journal of STD \& AIDS, 16, 395-403. http://dx.doi.org/10.1258/0956462054093962

[10] Owen-Smith, A., DiClemente, R. and Wingood, G. (2007) Complementary and Alternative Medicine Use Decreases Adherence to HAART in HIV-Positive Women. AIDS Care, 19, 589-593. http://dx.doi.org/10.1080/09540120701203279

[11] Owen Smith, A., DePadilla, L. and DiClemente, R. (2011) The Assessment of Complementary and Alternative Medicine Use among Individuals with HIV: A Systematic Review and Recommendations for Future Research. Journal of Alternative \& Complementary Medicine, 17, 789-796. http://dx.doi.org/10.1089/acm.2010.0669

[12] Littlewood, R.A. and Vanable, P.A. (2011) A Global Perspective on Complementary and Alternative Medicine Use among People Living with HIV/AIDS in the Era of Antiretroviral Treatment. Current HIV/AIDS Reports, 8, 257-268. http://dx.doi.org/10.1007/s11904-011-0090-8

[13] Fulk, L.J., Kane, B.E., Phillips, K.D., Bopp, C.M. and Hand, G.A. (2004) Depression in HIV-Infected Patients: Allopathic, Complementary, and Alternative Treatments. Journal of Psychosomatic Research, 57, 339-351. http://dx.doi.org/10.1016/j.jpsychores.2004.02.019

[14] Ojugwu, L.I. and Anah, C.O. (1981) Non-Hypertensive Renal Failure in Tropical Africa: A Different View. East African Medical Journal, 58, 660-666.

[15] Seedat, Y.K. (1978) Acute Renal Failure among Blacks and Indians in South Africa. South African Medical Journal, 54, 427-431.

[16] Bamgboye, E.L., Mabayoje, M.O., Odutola, T.A. and Mabadeje, A.F. (1993) Acute Renal Failure at the Lagos University Teaching Hospital: 10 Year Review. Ren Fail, 15, 77-80. http://dx.doi.org/10.3109/08860229309065577

[17] Gold, C.H. (1980) Acute Renal Failure from Herbal and Patent Remedies in Blacks. Clinical Nephrology, 14, $128-134$. 